\title{
PERFORMANCE-BASED FIRE DESIGN OF STEEL STRUCTURES OF HELSINKI OLYMPIC STADIUM
}

\author{
Mikko Salminen, Jukka Hietaniemi \\ Fire engineering and fire safety design consultants Markku Kauriala Ltd, Finland
}

\begin{abstract}
This paper presents an overview of the fire safety analysis conducted for the steel trusses of Helsinki Olympic Stadium stand. The analysis were conducted using advanced calculation models (FDS and SAFIR). It is shown that the predefined design solution (R60 fire protection with sprinklers) can be replaced by fire protection to class R15 (no sprinkler system) without sacrificing safety when some other passive protection means are applied. The good design solution in this case required highly iterative design process and smooth co-operation between client, architects, structural engineers and fire safety consultants.
\end{abstract}

Keywords: Performance-based fire design, structural analysis, steel structures

\section{INTRODUCTION}

Helsinki Olympic Stadium has been originally built in 1938. The most important events arranged in the history of this building were the XVth Olympic Games, 19. July - 3. August, 1952. As its maximum, in 1952, the Stadium accommodated 70000 spectators. Since its completion the Stadium has undergone eight major stages of development. Nowadays, after the basic renovation, the number of spectator places (all seats) is 39000 (www.stadion.fi, 2015). There is and will be a major renovation also between 2012 - 2018. One of the major changes will be that all the stands will be covered as shown in Figure 1.

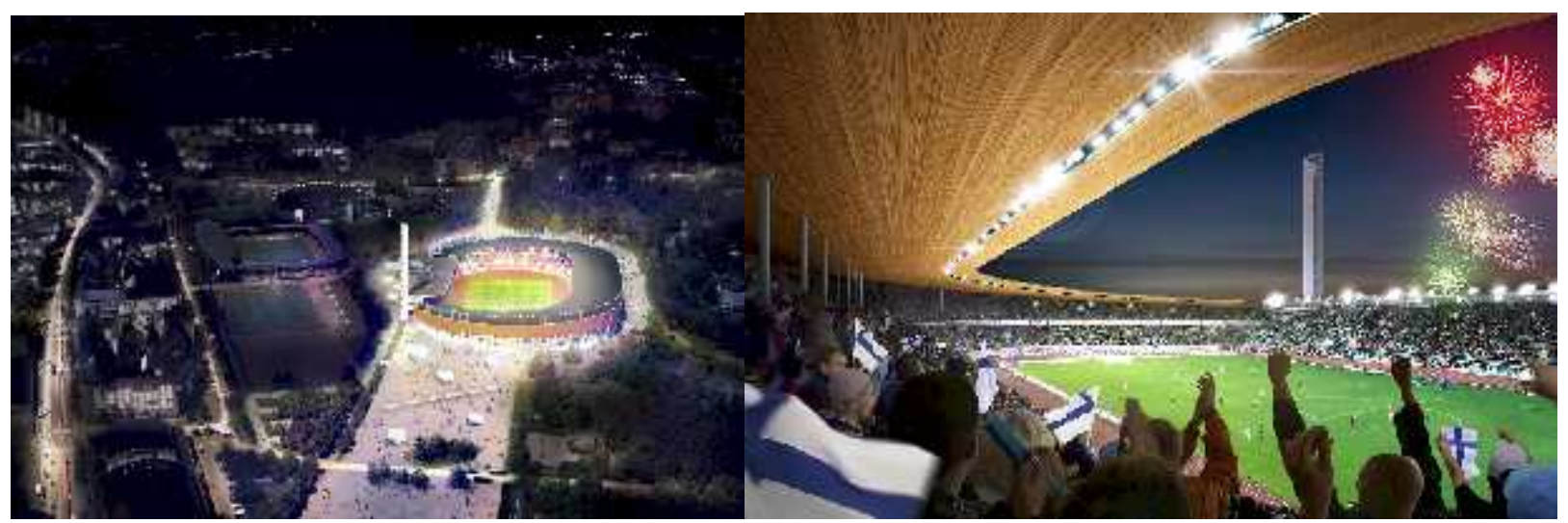

Fig. 1 Helsinki Olympic Stadium after 2012 - 2018 renovation (left) and the covered stand (right). Illustrations are provided by K2S Architects Ltd.

Helsinki Olympic stadium is an untypical, historical building. Thus, the prescribed fire regulations of Finland could not be used directly in this case. Finnish building regulations (Ymparistoministerio, 2011) enable the use of performance-based fire design and it was applied in many verifications in the considered building, such as evacuation simulations, smoke exhaust and fire resistance of load-bearing steel structures. The preliminary design conducted by other fire consultancy company concluded that the steel structures should be protected to 60 minutes of standard fire (R60) and that the steel trusses should also be protected using sprinkler system. When Markku Kauriala Ltd was appointed to this project, this solution was found to be highly conservative, expensive and difficult to apply in practise. 


\section{SCOPE OF THE ANALYSIS}

This paper presents an overview of the analyses that were conducted to verify the fire resistance of the line trusses shown in Figure 2. The fire resistance of transverse steel trusses, composite columns and steel braces were also defined in the project. However, based on the FDS-simulations, the line truss was found to be the most critical part of the structure in fire situation.

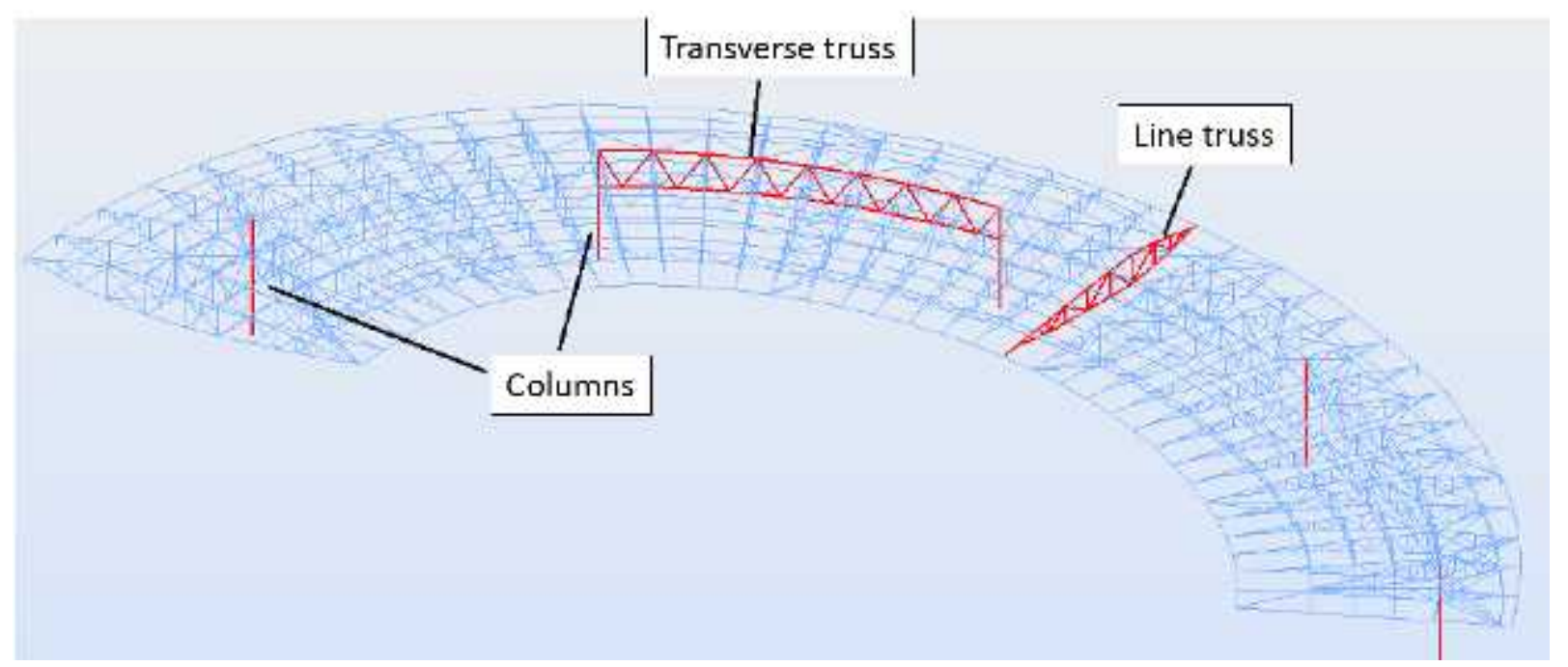

Fig. 2 Schematic drawing of the load-bearing steel structures of the stand roof. Illustration provided by Mr.

Eki Lehtimaki from Sweco Finland.

Figure 3 presents the main principle of the conducted analysis: first the adiabatic surface temperatures were defined using FDS-software (McGrattan et al, 2010). Then the temperatures of the cross-sections were defined and finally the structural behaviour of the truss was analysed. Thermal and structural analysis of the steel members were defined using SAFIR-software (Franssen, 2005). The design criteria for the considered structures was that they needed to maintain their load-bearing capacity during the design fire including the cooling phase.

\section{FDS- fire simulation $\quad$ 2. Steel profile temperatures}

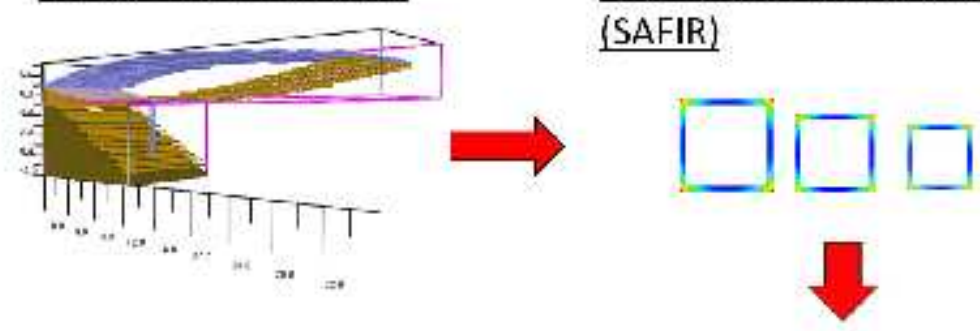

3. Structural behaviour (SAFIR)

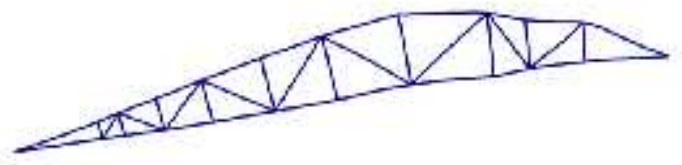

Fig. 3 Main principle of the conducted analysis. 


\section{NUMERICAL ANALYSIS}

\subsection{Fire simulations}

The temperature exposure of the structures was calculated by FDS5 fire simulation software, which is comprehensively validated and verified calculation tool for such fire cases as considered in the analysis. Fire and structural simulations was an iterative process where different combinations of wooden seats (fire classes B/D) and wooden cladding (fire classes B/D) of the truss were considered. As a result of the fire simulations the fire classes for the wooden seats and cladding were defined. Moreover, the upper part of the truss was protected with a fire resistant plate to block the direct flame contact to the truss members. Figure 4 presents the main features of the considered fire simulation model. Fire simulations revealed that the upper part of the stand is most critical in fire situation and that the fire exposure to the truss decreases clearly when the distance to the seats is longer. The fire location 4 was the most critical for the considered truss.

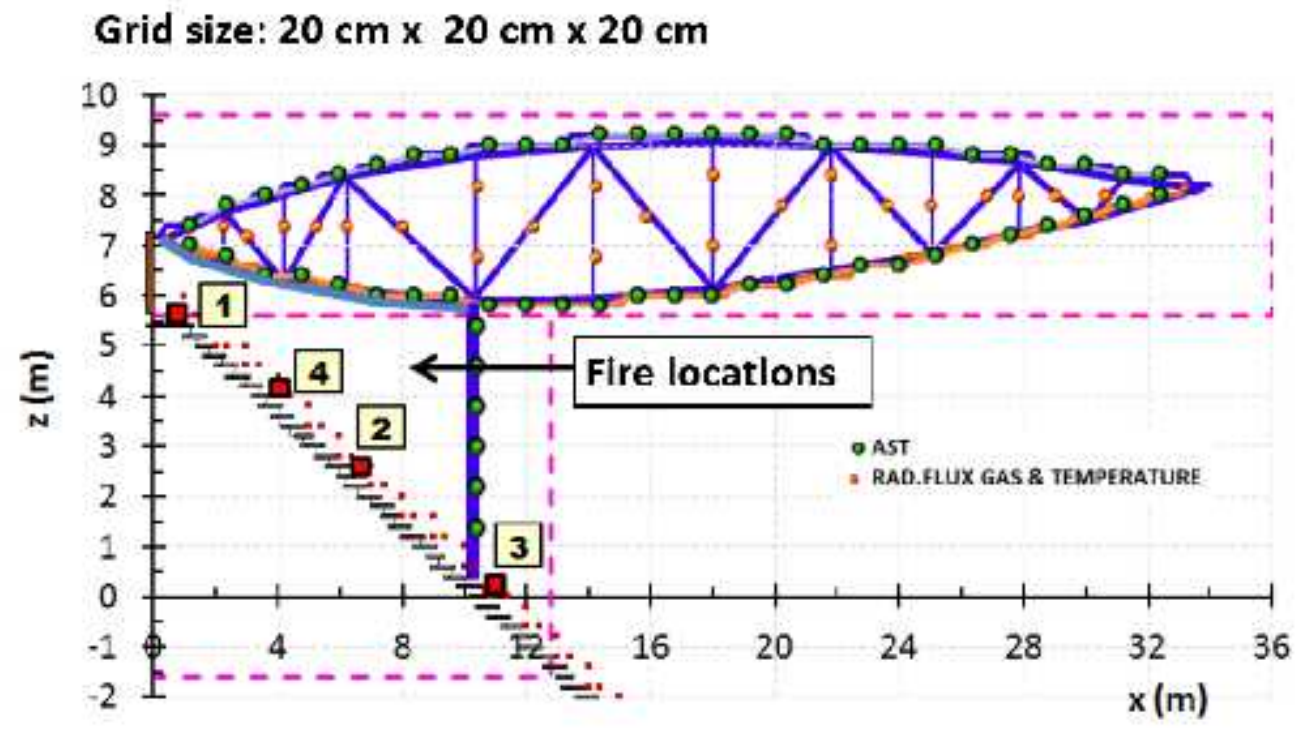

Fig. 4 Main features of the FDS-model.

\subsection{Structural analysis}

The structural analysis of the considered steel truss in fire situation were conducted using SAFIRsoftware (Franssen, 2005). The model consisted of 547 beam elements. All the applied values and temperature-dependent properties of steel (strength, elastic modulus, stress-strain curves, thermal conductivity, specific heat) were taken from the Eurocodes (EN 1991-1-2, 2002) and (EN 1993-1-2, 2005). Figure 5 presents the SAFIR-model of the considered structure. Table 1 shows the profiles of the truss. The steel grade of all profiles was S355. All the joints between truss members are welded, so they are modelled as rigid. The truss was modelled in $3 \mathrm{~d}$ in order to take buckling of the members towards the plane into account. The loading of the structure in fire situation was defined by the structural designer. 


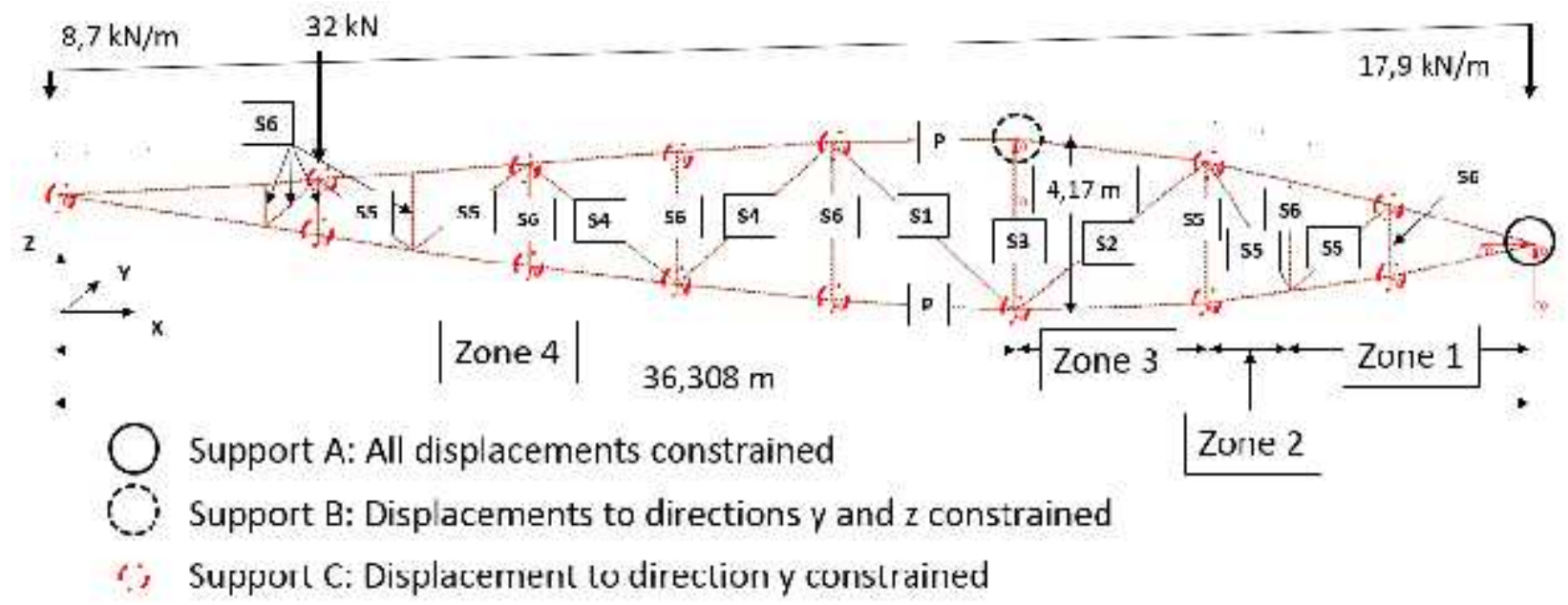

Fig. 5 Main features of the SAFIR-model.

Table 1 Profiles of the considered truss.

\begin{tabular}{|c|c|}
\hline Profile in Fig. 5 & Profile \\
\hline P & HEB260 \\
\hline S1 & CFRHS200x200x10 \\
\hline S2 & CFRHS180x180x10 \\
\hline S3 & CFRHS150x150x10 \\
\hline S4 & CFRHS140x140x8 \\
\hline S5 & CFRHS120x120x6 \\
\hline S6 & CFRHS100x100x6 \\
\hline
\end{tabular}

The structural model was compared to the model defined by the structural designer at ambient temperature. The maximum load defined by the structural designer corresponded very closely the load where the modelled truss started to yield. Moreover, the deflection profiles from the fire situation loading were basically the same in both models. Thus, it was concluded, that the SAFIRmodel corresponded the structural model.

\section{RESULTS}

Figure 6 presents the average temperatures of the hottest steel profiles at different zones defined in Fig. 5. The adiabatic surface temperatures at all the areas are also presented. In all zones the maximum adiabatic surface temperatures were applied conservatively for all edges of all steel members of the considered zone. 

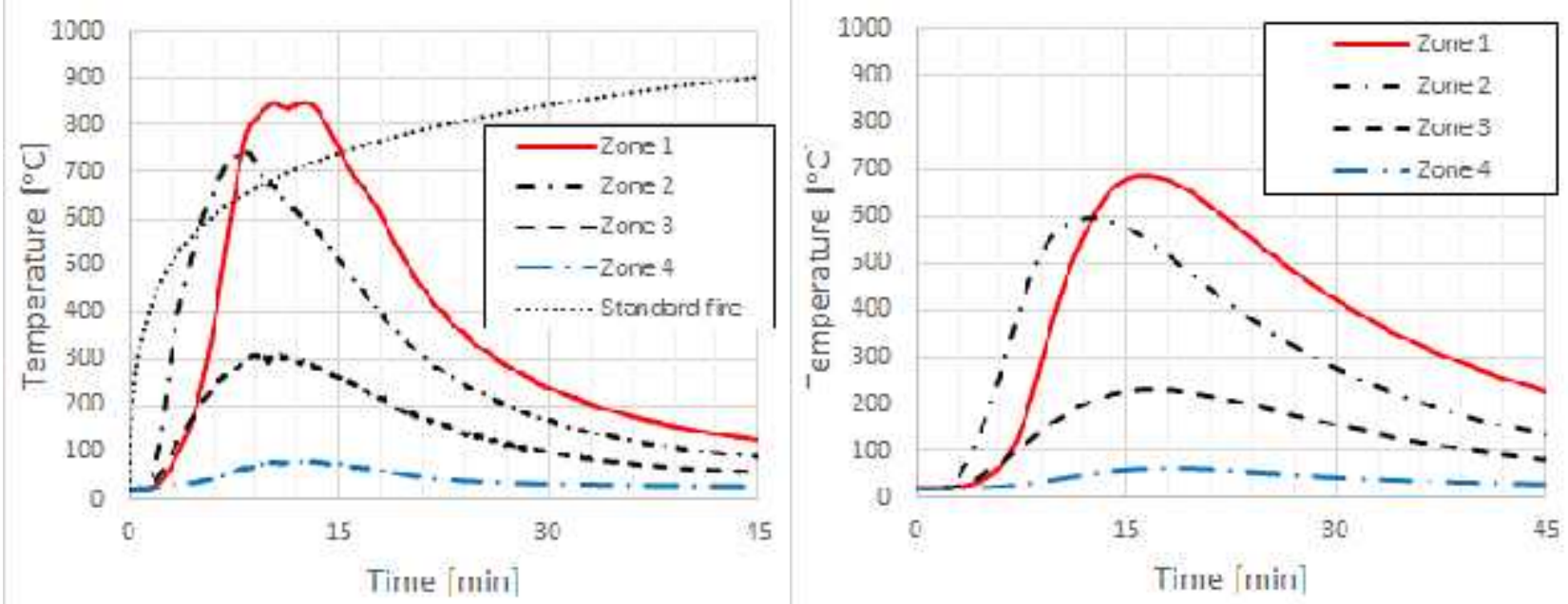

Fig. 6 Adiabatic surface temperatures (left) and steel profile temperatures (right) at different zones.

Based on Figure 6 it can be seen that in zones 1 and 2 the steel member temperatures can rise so high that the resistance of the members decreases clearly. In zones 3 and 4, the steel member temperatures were clearly lower. Figure 7 shows the maximum deflection of the considered truss in design fire as a function of time. Moreover, the same figure shows the results of conducted sensitivity analysis, which were the following:

- Case 1: Increase of the mechanical loads by $50 \%$

- Case 2: Increase of the cumulated heat flux in zone 1 by $50 \%$

- Case 3: Extension of the adiabatic surface temperatures of zone 1 to zone 2

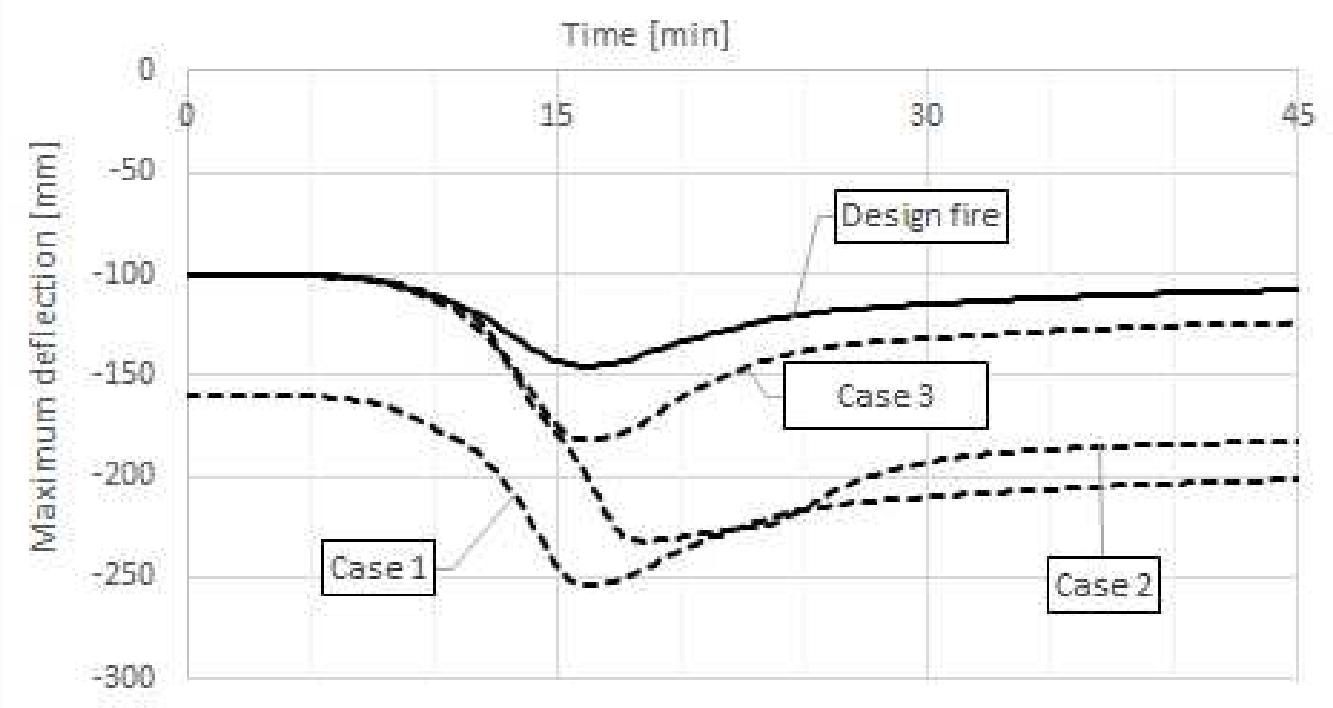

Fig. 7 Maximum deflection of the considered truss in design fire and the results of the sensitivity analysis.

Figure 7 shows that in the beginning of the design fire, the maximum deflection of the truss is approximately $100 \mathrm{~mm}$ and it reaches its maximum value, $145 \mathrm{~mm}$ at $17 \mathrm{~min}$. After 17 minutes, the deflection starts to decrease and it returns to almost same value as before the fire. It can be seen that the maximum deflection in design fire is not close to the often applied reference value $L / 20=1,18$ $\mathrm{m}$, where $L$ is in this case the length of the cantilever part of the truss. Based on the conducted sensitivity study, minor changes in thermal or mechanical loading do not have a considerable effect 
on the truss behaviour. Figure 8 presents the deformations of the truss (scaled by factor 75) at different times in the design fire.

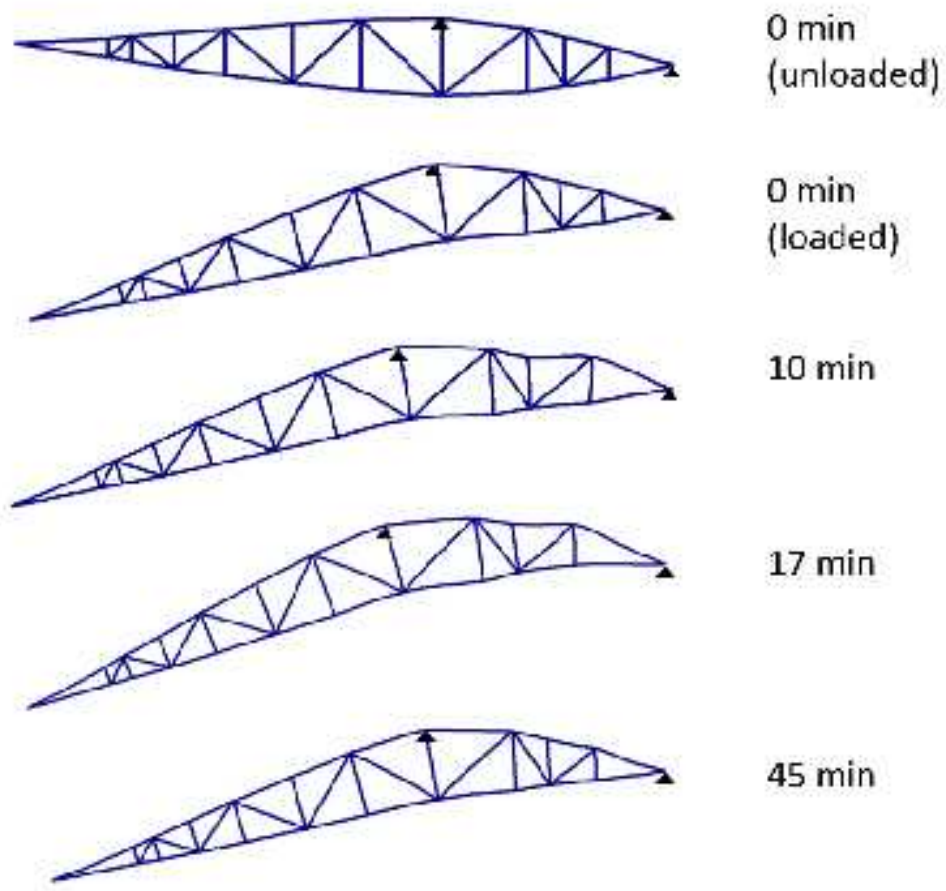

Fig. 8 Deformations of the truss during design fire.

\section{CONCLUSIONS}

The main conclusions of the work presented are listed below:

- Prescribed methods in fire engineering may lead to highly conservative and expensive solutions in some cases

- Significant benefits (cost-effectiveness, architectural issues, sustainability, etc.) can be achieved by using performance-based fire design without sacrificing safety

- Performance-based fire design in this case was highly iterative process which required smooth co-operation between client, architects, structural designers and fire safety consultants.

\section{ACKNOWLEDGMENTS}

The Stadium Foundation, K2S Architects Ltd. and Sweco Finland are gratefully acknowledged for providing material to this paper.

\section{REFERENCES}

EN 1991-1-2: 2002. Eurocode 1: Actions on structures, Part 1-2: General actions - Actions on structures exposed to fire. CEN. Brussels.

EN 1993-1-2: 2005. Eurocode 3: Design of steel structures. Part 1-2: Structural fire design. CEN. Brussels.

Franssen, J.-M. 2005. A Thermal/structural program modelling structures under fire. Engineering Journal, A.I.S.C. 2005; 42(3): 143-158.

Helsinki Olympic Stadium websites. www.stadion.fi (referred 26.6.2015).

McGrattan, K., McDermott, R., Hostikka, S., Floyd, J. 2010. Fire Dynamics Simulator (Version 5). User's Guide. Gaithersburg: National Institute of Standards and Technology (National Institute of Standards and Technology Special Publication 1019-5).

Ymparistoministerio. 2011. E1 SUOMEN RAKENTAMISMAARAYSKOKOELMA. Rakennusten paloturvallisuus. Maaraykset ja ohjeet 2011. Ymparistoministerion asetus rakennusten paloturvallisuudesta. In Finnish: The Finnish Building Regulations Concerning Fire Safety. 